\title{
Correction
}

\section{Correction: Tanaka, T., et al. Dual-Satellite Lunar Global Navigation System Using Multi-Epoch Double-Differenced Pseudorange Observations. Aerospace 2020, 7, 122}

\author{
Toshiki Tanaka $^{1, *}$, Takuji Ebinuma $^{2}$ and Shinichi Nakasuka ${ }^{1}$ \\ 1 Department of Aeronautics and Astronautics, University of Tokyo, 7-3-1 Hongo, Bunkyo-ku, Tokyo 113-8656, \\ Japan; nakasuka@space.t.u-tokyo.ac.jp \\ 2 Department of Astronautics and Aeronautics, Chubu University, 1200 Matsumoto-cho, Kasugai, \\ Aichi 487-8501, Japan; ebinuma@isc.chubu.ac.jp \\ * Correspondence: bump.bunny@gmail.com
}

Citation: Tanaka, T.; Ebinuma, T.; Nakasuka, S. Correction: Tanaka, T., et al. Dual-Satellite Lunar Global Navigation System Using Multi-Epoch Double-Differenced Pseudorange Observations. Aerospace 2020, 7, 122. Aerospace 2021, 8, 8 . https://doi.org/10.3390/aerospace80 10008

Received: 12 November 2020 Accepted: 17 November 2020 Published: 30 December 2020

Publisher's Note: MDPI stays neutral with regard to jurisdictional claims in published maps and institutional affiliations.

Copyright: () 2020 by the authors. Licensee MDPI, Basel, Switzerland. This article is an open access article distributed under the terms and conditions of the Creative Commons Attribution (CC BY) license (https://creativecommons.org/ licenses/by/4.0/).
The authors regret that this paper [1] contains typographical errors in the sentence between Equation (16) and Equation (17), as well as in Equations (18), (20), (21), (34), (36) and (37), with respect to the point that they use the wrong notations $t_{1}-t_{N}$, while the correct notations are $t_{k}-t_{k+N-1}$. The correct form is shown in Table 1 .

Table 1. Correct form of equations.

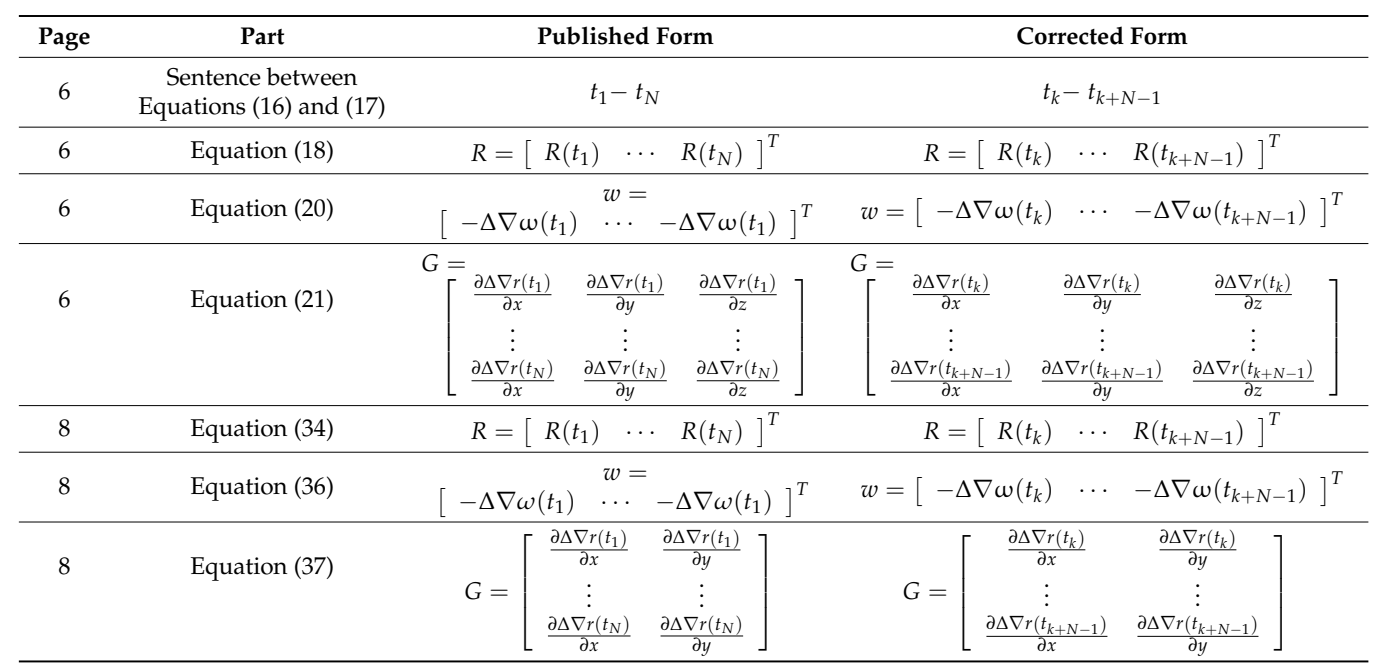

The error, not noticed during the proofreading process, was a simple mistype. The analytical developments and the results following these equations are in no way adversely affected by this typo. The authors would like to apologize for any inconvenience caused. The manuscript will be updated and the original will remain online on the article webpage.

\section{Reference}

1. Tanaka, T.; Ebinuma, T.; Nakasuka, S. Dual-Satellite Lunar Global Navigation System Using Multi-Epoch Double-Differenced Pseudorange Observations. Aerospace 2020, 7, 122. [CrossRef] 